\title{
BAHAGIA PERSPEKTIF SYED MUHAMMAD NAQUIB AL-ATTAS
}

\author{
Jarman Arroisi ${ }^{1}$, Novita Sari ${ }^{2 *}$ \\ ${ }^{1}$ Universitas Darussalam Gontor, INDONESIA \\ ${ }^{2}$ Universitas Darussalam Gontor, INDONESIA \\ *Correspondence: novitasarimmq7@gmail.com
}

\begin{abstract}
In facing life and life, the problem that mankind always feels is the two choices between Article History happiness and misery. A person who always thinks acts, and behaves positively can Received: 16-06-2020, certainly achieve positive results and get a sense of happiness. However, not a few Revised: 27-12-2020, people behave and behave negatively expecting positive results and wish to achieve a Accepted: 29-12-2020 sense of happiness. Instantaneous motivational trends like these are evidence that between reality and hope is often not linear. This text aims to explore the happy ideas of Keywords: Naquib al-Attas's perspective. By using the analytical descriptive method, this study Al-Attas; found several important conclusions. First, al-Attas divides the happy aspect into two Concetp ; types, namely the aspect of physical and spiritual happiness. Second, for al-Attas, the Happines; highest level of happiness is the level of someone who knows himself or makrifatullah. Ma'rifatullah Third, this highest happiness according to al-Attas cannot possibly be achieved by people who always emphasize the material aspects of their life, without knowing themselves, as is the case in modern-secular Western societies.

Abstrak

Dalam menghadapi hidup dan kehidupan, problem yang selalu dirasakan oleh ummat Histori Artikel manusia adalah dua pilihan antara bahagia dan sengsara.Seorang yang selalu berpikir, Diterima: 16-10-2020 bersikap, dan berprilaku positifdipastikan mampu meraih hasil positip dan memperoleh Direvisi: 27-12-2020 rasa bahagia. Namun demikian tidak sedikit orang bersikap dan berprilaku negatip Disetujui: 29-12-2020 mengharapkan hasil yang positip dan berandai meraih rasa bahagia.Tren motivasi yang serba instan seperti ini menjadi bukti antara realitas dan harapan lebih sering tidak linier. Kata Kunci: Naskah ini bertujuan mengeksplor ide bahagia perspektif Naquib al-Attas. Dengan Al-Attas; menggunakan metode deskriptip analitis kajian ini menemukan beberapa kesimpulan Kebahagiaan; penting. Pertama, al-Attas membagi aspek bahagia menjadi dua jenis yaitu aspek Konsep; kebahagiaan jasmani dan rohani. Kedua, bagi al-Attas tingkatan bahagia yang paling Ma'rifatullah tinggi adalah tingkatan seseorang yang mengenal dirinya atau makrifatullah. Ketiga, kebahagiaan yang tertinggi ini menurut al-Attas tidak mungkin bisa diraih oleh orangorangyang selalu menekankan aspek material dalam hidupnya, tanpa mengenal dirinya, seperti yang terjadi dalam masyarakat Barat modern-sekuler.
\end{abstract}

(C) 2020 Jarman Arroisi, Novita Sari

This work is licensed under a Creative Commons Attribution-ShareAlike 4.0 International License.

\section{A. Pendahuluan}

Bahagia identik dengan perasaan atau emosi seseorang. Orang yang bahagia adalah orang yang ditandai dalam hidupnya rasa cuku, merasa adanya kenikmatan dalam hidup, cinta, kepuasan dan kegembiraan yang intens. Rasa bahagaia yang sperti itu juga bisa diperoleh oleh setiap individu. Namun demikian, tidak sedikit makna bahagia lebih sering kali di definisikan hanya pada sesuatu yang bersifat materi tidak sampai kepada hal-hal yang mencakup metafisika. Terutama dalam era globalisasi saat ini, nilai kebahagiaan menjadi bervariasi tergantung dari kebutuhan manusia. Hal 
ini dapat di lihat dari eksistentsi manusia sebagai makhluk mikrokosmos yang terbagi menjadi lima eksitensi yakni, jasadi, nabati, hewani, insani dan ruhani. ${ }^{1}$

Dalam pemikiran Barat istilah kebahagiaan (happines) ini di fokuskan dalam kajian yang disebut dengan psikologi positif. Dalam aliran psikologi positif inilah para psikolog Barat merumuskan makna dari happines (kebahagiaan) yang mereka masukan dalam pembahasan Psychology Well Being.Dalam memaknai kebahagiaan ini, manusia lebih dominan untuk mendapatkan kebahagian psikologis, dimana kebahagiaan ini hanya bersifat sementara dan tidak memberikan keseimbangan terhadap individu manusia, karena yang di bahagiakan adalah hasrat semata. Contoh dapat di lihat dalam penelitian yang berjudul The Paradoxical Effects of Pursuing Positive Emotion, psikolog Brett Q. Ford dan Iris B. Mauss ${ }^{2}$, dalam penelitian ini psikolog membagi responden menjadi dua kelompok, kelompok pertama terdiri dari responden yang diminta untuk membuat diri mereka sebahagia mungkin sambil mendengarkan musik, sedangkan kelompok kedua di minta hanya sekedar mendengarkan musik. Dari penelitian ini kemudian disimpulkan bahwa responden yang di berikan target untuk bahagia justru tidak mendapatkan perasaan yang bahagia. Hal ini kemudian memberikan hasil penelitian yang di jelaskan oleh Brett dan Iris bahwa perasaaan bahagia merupakan sesuatu yang bersifat sementara, mengejar dan menargetkan kebahagiaan itu akan menjadi sebuah induksi yang berbahaya. Dari penelitian ini dapat di lihat bahwa konsep kebahagiaan yang banyak di pahami oleh kebanyakan orang itu merupakan konsep kebahagiaan yang hanya berorientasi pada kebahagiaan duniawi dan menghilangkan nilai keyakinan dan sifat-sifat ketuhanan.

Urgensi adanya penelitian ini adalah untuk memberikan pejelasan secara tekstual dan kotekstual mengenai konsep kehagiaan. Hal ini dilatar belakangi oleh maraknya manusia modern yang saat ini hilang arah bahkan tidak mampu mencapai kebahagiaan sesusungguhnya, karena tertutupi dengan orientasi duniawi. Pentingnya penelitian ini juga dapat dilihat dari kajian terdahulu yang juga membahas mengenai konsep kebahagiaan dan relevan dalam penelitian ini. Pertama, penelitian Rofi'udin, Konsep Kebahagiaan dalam Pandangan Psikologi Sufistik. Penelitian ini mengkaji mengenai aspek kebahagiaan dalam psikologi sufistik dan membandingkan dengan psikologi kontemporer. Aspek kebahagiaan dalam psikologi sufistik menitik beratkan pada nilai etis transendental yang di maknai bahwa kebahagian itu merupakan anugrah Allah dan bukan berasal dari usaha manusia. ${ }^{3}$ Kedua, penelitian Kholili Hasib, Manusia dan Kebahagiaan: Pandangan Filsafat Yunani dan Respon Syed Muhammada Naquib al-Attas. Penelitian ini membahas mengenai konsep tentang manusia dan kebahagiaan, manusia dituntut untuk mengetahui hakikat dari konsep manusia itu untuk mencapai kebahagiaan yang hakiki, karena dengan menusia memahami hakikatnya maka ia akan memposisikan dirinya sesuai dengan syariat Islam atau dalam hal ini sesuai dengan worldview Islam. ${ }^{4}$ Ketiga, penelitian yang dilakukan oleh Jarman Arroisi, Kebahagiaan dalam Perspektif Al-Ghazali. Penelitian ini menjelaskan tentang konsep kebahagiaan perspektif al-Ghazali. Dalam kajian ini peneliti menjelaskan puncak kebahagiaan seseorang menurut al-Chazali adalah sampainya seseorang kepada tingkat ma'rifah Allah (mengenal Allah).

\footnotetext{
${ }^{1}$ Komaruddin Hidayat, Psikologi Kebahagian Merawat Bahagia Tiada Akhir (Jakarta: Books, 2013 ), 8.

${ }^{2}$ lihat:https://Oxford.Universitypressscholarship.Com/View/10.1093/Acprof:Oso/9780199926725.001.0001/Acp rof-9780199926725-Chapter-20 n.d.

${ }^{3}$ Rofi'udin, “Konsep Kebahagiaan Dalam Pandangan Psikologi Sufistik,” Theologia 24, no. 2 (2013): 1-37.

${ }^{4}$ Kholili Hasib, "Manusia Dan Kebahagiaan: Pandangan Filsafat Yunani Dan Respon Syed Muhammad Naquib Al-Attas," Tasfiyah 3, no. 1 (2019): 21, https://doi.org/10.21111/tasfiyah.v3i1.2980.
} 
Sehingga orientasi dari kebahagiaan itu tidak hanya pada kebutuhan materi tapi lebih dari itu, yakni kebahagiaan rohani dengan menganal Allah swt. ${ }^{5}$

Dari ketiga penelti di atas tampak lebih jelas bahwa menurut tokoh yang dikaji dalam penelitian itu,aspek non material adalah aspek penting yang perlu diperhatikan oleh pencari rasa bahagia. Selain itu, para penelti tidak menjelaskan secara detail mengenai tingkatan dan tahapan yang mesti dilakukan oleh seseorang yang berharap mendapatkan rasa bahagia. Atas dasar pertimbangan tersebut, kajian ini menjadi lebih menarikketika ide atau konsep bahagia itu tidak hanya dilihat dari aspek non materi dan metode serta tahapan memperolehnya. Tetapi yang lebih penting adalah bagaimana urgennya masyarakat Barat modern-sekuler itu mampu memperolah bahagia dengan cara yang benar. Pandangan hidup adalah poin penting dari ide al-Attas yang perlu diteliti dalam naskah ini.

\section{B. Metode Penelitian}

Metode yang digunakan peneliti dalam kajian ini adalah penelitian kualitatif. ${ }^{6}$ Dalam hal ini analisis muatan lebih dekat dengan analisis wacana yang dimaksudkan sebagai metode analisis data dan metode tafsir teks. ${ }^{7}$ Artinya dalam analisis data pada hakikatnya peneliti memberikan penafsiran terhadap gagasan primer dan dikonfrontasikan dengan gagasan primer lainnya atau gagasan sekunder.

Selain itu, kajian ini juga menggunakan jenis penelitian kepustakaan (library research). ${ }^{8}$ Dalam kontek ini metode kepustakaan yang digunakan lebih menekankan pada aspek tekstual ${ }^{9}$ seperti buku, makalah, jurnal, catatan, maupun laporan hasil penulisan dari penulisan terdahulu ${ }^{10}$ dan sumbersumber pustaka lainnya. Berdasarkan subjek matter-nya, menurut M. Atho Mudzar, kajian ini dapat dikategorikan dalam kajian budaya. Kajian budaya merupakan sebuah model penulisan yang memiliki konsen terhadap pemikiran, nilai-nilai dan ide budaya sebagai produk berpikir manusia. ${ }^{11}$ Disamping itu berdasarkan rumusan masalah, kajian ini berkaitan dengan fenomena sosial, budaya, seni dan filsafat secara interdisipliner. ${ }^{12}$

Dalam menganalisa data penulis menggunakan metode deskriptif untuk mengelola data secara sistematis ${ }^{13}$ menguraikan keadaan suatu komunitas. ${ }^{14}$ Penganalisaan data dilakukan secara seksama dan diklasifikasikan menurut variable yang dibutuhkan. ${ }^{15}$ Analisa data menggunakan metode deskriptif dirasa sesuai dengan tujuan penelitian yaitu mengetahui konsep kebahagiaan al-Attas

\footnotetext{
5Jarman Arroisi, “Bahagia Dalam Perspektif Al-Ghazali,” Kalimah 17, no. 1 (2019): 89, https://doi.org/10.21111/klm.v17i1.2942.

${ }^{6}$ Ronny Kountur, Metode Penelitian Untuk Penulisan Skripsi Dan Tesis (Jakarta: Buana Printing, 2009), 105.

${ }^{7}$ Mudjia Rahardjo, Analisis Muatan Sebagai Metode Pengukuran Kata Pengantar Dalam Nanang Martono, "Metode Penelitian Kualitatif Analisis Isi Dan Analisis Data Sekunder (Jakarta: PT Raja Gravindo Persada, 2014$), 1$.

${ }^{8}$ Kaelan, Metodologi Penelitian Kualitatif Interdisipliner Bidang Sosial, Budaya, Filsafat, Seni, Agama Dan Humaniora (Yogyakarta: Paradigma, 2012), 148.Lihat juga Henri J. Koren, Research in Philosophy (USA: Dequesne University, 1966), 151.

${ }^{9}$ Masri Singarimbun, Metodologi Penulisan Survey (Jakarta: LP3ES, n.d.), 45.

${ }^{10}$ M. Iqbal Hasan, Pokok-Pokok Materi Penulisan Dan Aplikasinya (Jakarta: Ghalia Indonesia, 2002), 3.

${ }^{11}$ M. Aatho Mudzar, Pendekatan Studi Islam Dalam Teori Dan Praktek (Yogyakarta: Pustaka Pelajar, 1992), 37.Lihay juga: Mahmud Arif, Pendidikan Islam Transformatif (Yogyakarta: LKis, n.d.), 10.

${ }^{12}$ Kaelan, Metodologi Penelitian Kualitatif Interdisipliner Bidang Sosial, Budaya, Filsafat, Seni, Agama Dan Humaniora, 63.

${ }^{13}$ Sudarwan Danim, Riset Keperawatan: Sejarah Dan Metodologi (Jakarta: Buku Kedokteran EGC, 2002$), 52$.

${ }^{14}$ Budiarta, Metodologi Penelitian Kesehatan Dengan Contoh Bidang Ilmu Kesehatan Gigi (Jakarta: Buku Kedokteran EGC, 2006).

${ }^{15}$ Abuddin Nata, Metodologi Studi Islam (Jakarta: Raja Wali Press, 2013), 210.
} 
dalam bentuk sistem pemikirannya ${ }^{16}$ dan pengaruhnya terhadap sikap dan pandangan suatu kelompok. ${ }^{17}$

\section{Pembahasan atau Analisis}

\section{Pengertian Bahagia}

Untuk membantu mengetahui dan memahami pengertian bahagia, disini peneti menyampaikan arti bahagian dari berbagi perspektif. Secara umum, arti bahagia dalam Oxford Englis Dictionary disebutkan memeiliki arti happiness sebagai "Good fortune or luck ini life of in particular affair; success, prosperity." ${ }^{18}$ Dalam definisi ini kebahagiaan merupakan sesuatu yang ada diluar manusia, dan bersifat kondisional, kebahagiaan juga bersifat temporal. Dalam kamus Bahasa Indonesia kata bahagia dapat di artikan sebagai keadaaan atau perasaan senang, tentram dan terbebas dari segala yang menyusahkan. ${ }^{19}$

Aristoteles menyatakan kebahagiaan merupakan tujuan dalam kehidupan manusia. ${ }^{20}$ Kebahagiaan juga merupakan standar pencapaian seseorang dengan tercapainya standar itu maka tidak ada lagi keinginan dari manusia. Menurutnya, kebahagiaan itu bisa terlaksana jika manusia memiliki jiwa yang baik. ${ }^{21}$ Dalam hal ini nilai kebahagiaan (eudaimonia) akan di dapa melalui aktivitas level tinggi yakni dengan menjalankan aktivitas berdasarkan ajaran keutamaan.

Manusia dapat mencapai sesuatu ketika ia mengerti terlebih dahulu apa yang ingin dicapai, begitupun kebahagiaan. Kebahagiaan sering didefinisikan sebagai suatu kesenangan, ketentraman hidup, serta keberuntungan yang bersifat lahir dan batin. ${ }^{22}$ Dalam istilah bahasa Inggris dikenal kata happiness yaitu sebuah keadaan menyenangkan, keberuntungan dan kemakmuran, serta anugerah. ${ }^{23}$ Kebahahagiaan dalam pandangan Martin Seligman dikenal dengan authentic happiness.Kebahagiaan ditandai dengan emosi positif, kepuasan hidup yang berlimpah serta kehidupan yang bermakna. ${ }^{24}$ Kebahagiaan ini adalah ketika seseorang berada dalam keadaan gratifikasi, yaitu keadaan hanyut dalam suatu pekerjaan yang disukai namun tidak bisa menjelaskan secara jelas emosi yang dirasakannya ketika itu.Maka keadaan positif dalam hidup dan bermakna sehingga larut dalam perasaan itu merupakan titik authentic happiness.

Selain itu, istilah well-being digunakan untuk menggambarkan kebahagiaan.Istilah ini lazim digunakan dalam literatur psikologi sebagai kata ganti kebahagiaan ${ }^{25}$ yang memiliki arti kesejateraan dan kualitas hidup.Selanjutnya berkembang istilah psycological well-being yaitu sebuah kualitas individu yang puas tehadap hidupnya ${ }^{26}$ serta subjective well-being yang merupakan evaluasi terhadap masa lalu meliputi kebahagiaan dan kepuasan suatu hal. ${ }^{27}$ Kebahagiaan yang

\footnotetext{
${ }^{16}$ Moh. Nazir, Metode Penelitian, ed. Risman F. Sikumbang, Cet-8 (Bogor: Ghalia Indonesia, 2013 ), 106.

${ }^{17}$ Gunawan Sumodiningrat, Pemberdayaan Sosial: Kajian Ringkas Tentang Pembangunan Manusia Indonesia (Jakarta: Buku Kompas, n.d.), 4.

${ }^{18}$ Lihat:"Https://Www.Oxfordlearnersdictionaries.Com/Definition/English/Happiness?Q=happiness.," n.d.

${ }^{19}$ Pusat Bahasa Departemen Pendidikan Nasiona, Kamus Bahasa Indonesia (Jakarta: Pusat Bahasa, 2008), 115.

${ }^{20}$ Aristotle, "Nicomachean Ethic," in Book I Terj. Roger Crisp (UK: Cambridge University Press, n.d.), 5-6.

${ }^{21}$ Kees Bertens, Sejarah Filsafat Yunani (Yogyakarta: Kanisius, n.d.), 108.

${ }^{22}$ Departemen Pendidikan dan Kebudayaan, Kamus Besar Bahasa Indonesia (Jakarta: Balai Pustaka, 1990), 65.

${ }^{23}$ S. Stephenson Smith, The New International Webster's Comprehensive Dictionary Of The English Language: Deluxe Encyclopedic Ed (Chicago: J.G. Ferguson Publishing, 1996), 573.

${ }^{24}$ Martin Seligman, , Authentic Happiness: Using the New Positive Psychology to Realize Your Potential for Lasting Fulfillment. (New York: Free Press, 2002), 249.

${ }^{25}$ C.R. Snyder \& Shane J Lopez, Positive Psycology: The Saintific And Practical Exploration Of Human Strenght (California: Sage Publication, 2007), 129.

${ }^{26}$ C.D Ryff, "Happiness Is Everything, Or Is It? Explorations On The Meaning Of Psychological Well-Being," Journal Of Personality And Social Psychology Vol. 57 (1989): 1069-81.

${ }^{27}$ Ed Diener, Personality, Culture, and Subjective Well Being of Nation (Chicago: The University of Chicago Press, 2009), 1.
} 
dimaksud bukan hanya berdasar aspek emosional yang subjektif, melainkan juga objektif menyangkut pengembangan selurah aspek kemanusiaan suatu individu (aspek moral, sosial, emosional, rohani). ${ }^{28}$ Maka kebahagiaan sebagai keadaan kesejahteraan ataukepuasan, dan pengalaman yang menyenangkan atau memuaskan ${ }^{29}$. Definisi dari Haidar Bagir menyatakan bahwa kebahagiaan tersusun dari tiga aspek, pertama, Kesejahteraan(well-being) yakni kepuasaan atau pemenuhan terhadap sesuatu yang di anggap penting dalam hidup (eksternal). Kedua, adanya kerelaan terhadap keadaan yang didalam dirinya (internal). Ketiga, perasaan mengetahui makna hidup yakni di landasi dengan kedekatan dengan Tuhan. ${ }^{30}$

Dalam Islam istilah bahagia lebih sering diartikan dengan ungkapan kata sa'ādah. Sa'ādah secara bahasa berasal dari akar kata (سـد) yang berarti bahagia. ${ }^{31}$ Menggunakan kata sa 'ádahmemiliki dua dimensi yaitu, akhirat (ukhrawiyyah) dan dunia (dunyawiyyah). ${ }^{32}$ Memahami suatu istilah penting juga melalui pemahaman terhadap lawan istilah tersebut. Kata syaqāwah yang berarti kesengsaraan, kemalangan, kecelakaan menjadi lawan kata sa'ādah ${ }^{33}$. Kata ini memilki turunan kata khawf (takut), huzn (sedih), dank (kesempitan, kesengsaraan jiwa). Istilah syaqāwah adalah istilah umum yang meliputi semua bentuk kesengsaraan sehingga istilah lain yang lebih rinci menjadi unsur dari syaqāwah itu sendiri. ${ }^{34}$ Oleh sebab itu segala sesuatu yang bertentangan dari instrumen syaqāwah merupakan kebahagiaan.

Al-Quran menjadi sumber utama penafsiran mengenai kebahagiaan. Kata sa'ädah yang digunakan dalam menginterpretasikan bahagia disebutkan dua kali dalam Al-Quran yaitu surah Hud ayat 105 dan 108.

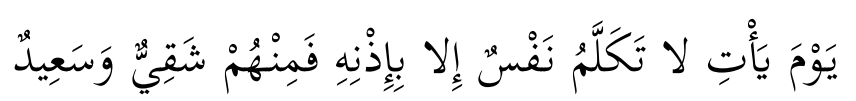

Di kala datang hari itu, tidak ada seorang pun yang berbicara, melainkan dengan izin-Nya; maka di antara mereka ada yang celaka dan ada yang berbahagia. (Hud:105)

Ayat ini menyiratkan bahwa bahagia dirasakan diwaktu akhirat. Maka terlihat atas izin Allah manusia akan dikumpulkan dihari kiamat kelak dalam dua keadaan ada yang celaka ataupun bahagia. ${ }^{35}$ Tafsir Ibnu Katsir menyebutkan "di antara mereka yang dihimpunkan pada hari perhimpunan itu ada yang celaka, ada pula yang berbahagia. perihalnya sama dengan yang disebutkan dalam ayat lain melalui firman-Nya: Segolongan masuk surga dan segolongan masuk neraka". ${ }^{36}$ Maka di dapatkan bahwa keadaan bahagia merupakan lawan dari keadaan celaka atau sengsara, dan keduanya dirasakan diwaktu hari penghimpunan (akhirat). Lalu pada penyebutan kata sa'ādah diayat 108 yang berbunyi

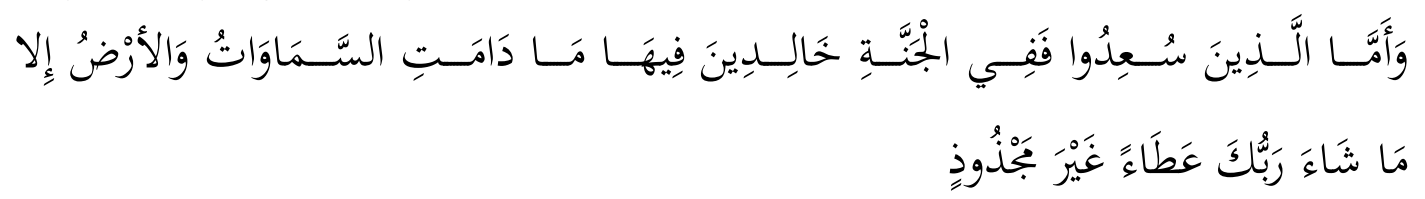

\footnotetext{
${ }^{28}$ Bertens, Sejarah Filsafat Yunani, 108.

29“"Https://Www.Merriam-Webster.Com/," The Merriam Webster Online Dictionary, n.d.

${ }^{30}$ Syahril Syam, Secret of Attaractor Factor (Jakarta: Gramedia, 2008), 49.

${ }^{31}$ Muhammad bin Mukrim bin Manzur, Lisānul Arab (Beirut: Dār Șadir, n.d.), 311.

${ }^{32}$ Syed Muhammad Naquib Al-Attas, Prolegomena, 1st ed. (Kuala Lumpur: ISTACT, 1996), 92.

${ }^{33}$ Muhammad ibn Mukarrim ibn Manzur al-Anshari al-Ifriqi Al-Minsari, Lisan Al-Arab (Kairo: Dar Ibn al-Jauzi, 2015), 438.

${ }^{34}$ Syed Muhammad Naquib Al-Attas, "Islam: The Concept of Religion and the Foundation of Ethics and Morality," Prolegomena to The Metaphysics of Islam: An Exposition of the Fundamental Elements of the Worldview of Islam, 1995, 358.

${ }^{35}$ Jalal al-Din al-Mahalli dan Jalal al-Din Al-Suyuți, Tafsir Al-Jalalayn (Cairo: Dar al-Hadist, n.d.), 300.

${ }^{36}$ Ibnu Katsir, Tafsîr Al-Qur'an Al-Adhim (T.Kota: Dar Tayyibah, 1999), 150.
} 
Adapun orang-orang yang berbahagia, maka tempatnya di dalam surga mereka kekal di dalamnya selama ada langit dan bumi, kecuali jika Tuhanmu menghendaki (yang lain); sebagai karunia yang tiada putus-putusnya. (QS. Hud: 108)

Orang yang bahagia adalah mereka yang mengikuti risalah Rasul dan bagi mereka surga sebagai tempat kembali dan kekal disana. ${ }^{37}$ Model kebahagian semacam ini menurut Wahbah, hanya bisa diraih dengan perbuatan baik yang telah dikehendaki. ${ }^{38} \mathrm{Hal}$ ini juga sejalan dengan pengertian kebahagiaan yang ditekankan oleh al-Farabi. Dalam kaitan ini al-Farabi menyatakan berpikir merupakan perilaku yang dapat mewujudkan kebahagiaan. ${ }^{39}$ Ini berarti ada hubungan yang erat antara akhlak dan pengetahuan rasional.

Apa yang disampaikan oleh Wahbah dan al-Farabi di atas sejalan dengan pokok pemikiran Syed Muhammad Naquib al-Attas. Dalam hal ini al-Attas menjelaskan secara gamblang dan lebih rinci mengenai makna bahagia. Menurutnya bahagia itu tidak hanya tertuju pada entitas jasmani manusia saja, bukan pula pada pikiran manusia, tetapi sesungguhnya bahagia itu bisa diperoleh dengan meyakini atas hak Allah dan mengerjakan tindakan-tindakan positip yang sesuai dengan keyakinan itu sendiri. ${ }^{40}$

Selain itu, menurut al-Attas, hal penting yang perlu diperhatikan dalam memperolah rasa bahagia adalah agama menjadi asas pokok yang tidak boleh dilupakan. Dalam beragama integrasi antara akal dan nakl merupkan hal yang mesti dilakukan. Dengan akal manusia mampu memikirkan apa yang telah diwahyukan dalam kitabNya. Dan dengan akal pula seseorang mampu memahami dan mengartikulasikan apa-apa yang ada dalam kitab itu. Termasuk bagaimana seseorang mengartikulasikan makna bahagian dalam hidup dan kehidupan ini. Dalam hal ini al-Attas menjelaskan bahwa bahagia merupakan rasa senang yang berdasarkan pada ilmu, iman dan perbuatan yang berupa akhlak yang baik. Ilmu dan iman merupakan kebenaran yang akan membawa manusia untuk membedakan mana hal yang baik dan mana hal yang buruk sehingga manusia mampu menghasilkan sebuah kondisi yang disebut dengan adil. ${ }^{41}$

Berdasarkan uraian diatas dapat disampaikan disini kebahagiaan merupakan tujuan hidup setiap manusia. Semua orang mendambagakan rasa bahagia, senang, keberuntungan, serta kemakmuran.Dalam istilah psikologi kebahagiaan diukur dengan kualitas hidup dan kesejahteraan. Sedangkan dalam Islam kebahagiaan dipandang dalam dua dimensi yakni dimensi dunia dan akhirat, dunia sebagai tempat investasi kebahagiaan di akhirat. Sehingga kebahagiaan itu tidak hanya berfokus pada aspek materi tetapi lebih mendalam dari itu, yakni ada unsur rohani didalamnya.

\section{Agama Sebagai Landasan Bahagia}

Manusia adalah makhluk yang terdiri dari dua entitas yakni jasad dan ruh, artinya manusia ini adalah makhluk jasadiah dan ruhaniah. Dalam hubungan kebahagiaan antara jasadiah dan ruhaniah ini memerlukan usaha dan perlakukan yang berbeda. Misalnya untuk mencapai kebahagiaan jasadiah manusia menginginkan kesuksesan hidup berupa kekayaan, kesejahteraan, kehormatan dan

\footnotetext{
${ }^{37}$ Al-Suyuți, Tafsir Al-Jalalayn, 351.

${ }^{38}$ Wahbah Al-Zuhaili, No Title (Damaskus: Dar al Fikr al-Mu'ashir, n.d.), 150.

${ }^{39}$ Muhammad 'Utsman Najati, Jiwa Dalam Pandangan Filosof Muslim, Terj:Dazi Saloom (Bandung: Pustaka Hidayah, 2002), 77.

${ }^{40}$ Syed Muhammad Naquib al-Attas, Ma'na Kebahagiaan Dan Pengamalannya Dalam Islam (Kuala Lumpur: ISTACT, 2002), 4.

${ }^{41}$ Syed Muhammad Naquib al-Attas, Islam Dan Sekularisme (Bandung: PIMPIN, 2011), 93.
} 
lain-lain. ${ }^{42}$ Berbeda dengan pemenuhan kebahagiaan ruhaniah, untuk mencapai kebahagiaan manusia memerlukan ketenangan, kedamaian, serta kelapangan hati dalam menjalani kehidupan. Kebahagiaan ruhaniah akan di dapatkan dari ketundukan manusia kepada Tuhan. ${ }^{43}$ Namun, dalam era globalisasi saat ini dan semakin banyaknya kebutuhan hidup manusia, menjadikan nilai kebahagiaan yang di cari manusia saat ini adalah kebahagiaan yang berifat materi. Hal ini dibuktikan dari penelitian empiris yang meyatakan bahwa kebahagiaan merupakan hal yang terdiri dari kesenangan, dan kepuasan hidup. ${ }^{44}$

Manusia dan psikologinya jika dipandang dalam pemikiran Barat berorintasi pada aspek empiris, yakni pemenuhan akan kebutuhan duniawinya. Contoh dalam pemikiran Richard M. Ryan yang menyatakan bahwa kebahagiaan itu identik dengan pandangan hedonistis yakni unsur kebahagiaan hanya dari kesenangan belaka (pleasure). ${ }^{45} \mathrm{John}$ Stuart Mill seorang penganut utilitarisme meyatakan bahwa kebahagiaan adalah nikmat dan kebebasan dari perasaan yang tidak enak karena itulah yang selalu diinginkan manusia. ia menyatakan bahwa nilai primer bagi manusia adalah kebahagiaan dan kebahagiaan itu terdiri dari pengalaman nikmat dan kebebasan dari perasaan sakit. ${ }^{46}$ Berbeda dengan Stuart, Plato membagi manusia terdiri atas jiwa dan badan. Badan adalah wadah jiwa, sedangakn realitas yang sebanarnya adalah jiwa. Menurut plato, gerak jiwa untuk meraih kebahagiaan harus mengarah pada sesuatu diluar diri manusia yang biasanya disebut dengan Tuhan. ${ }^{47}$ artinya, Plato mempercayai hal-hal transenden diluar dirinya yang bisa menjadi sumber kebahagiaan dan keutamaan bagi diri manusia.

Aristoteles juga memberikan konsep mengenai manusia dan psikologinya, dalam pandangan Aristoteles manusia itu merupakan makhluk hidup yang mempunyai jiwa dan badan. Jiwa merupakan prinsip hidup dan ia akan terus hidup sesudah kematian. Sedangkan badan merupakan materi dari jiwa yang memiliki potensi dan aktualisasi diri dalam bentuk perbuatan. ${ }^{48}$ Sehingga Aristoteles menyatakan bahwa manusia itu memiliki tujuan, yakni nilai kebahagiaan. Nilai kebahagiaan yang dimaksud adalah kebahagiaan yang berlandaskan pada nilai moral (etika). Maka jika manusia ingin bahagia makan maka harus menjalankan ajaran "keutamaan" yang didasari dari intelektual dan moral, yakni integrasi antara rasio dan moral.

Merespon dari konsep manusia dan psikologi dalam pandangan Barat al-Attas memformulasikan konsep manusia dan psikologi dalam pandangan Islam (Worldview Islam). AlAttas menyatakan bahwa manusia itu terdiri dari entitas dan subtansi spiritual manusia yang berupa hati, jiwa, ruh dan akal. ${ }^{49}$ Dalam aspek psikologinya manusia merupakan kebutuhan jasmani dan rohani.Kebutuhan jasmani terpenuhi dengan makanan, pakaian dan tempat tinggal.Sedangakan kebutuhan rohani di butuhkan manusia berupa kebutuhan kepada kesehatan jiwa dan kekuatan

\footnotetext{
${ }^{42}$ Sahrul Mauludi, Aristoteles Inspirasi Dan Pencerahan Untuk Hidup Lebih Bermakna (Jakarta: T Elex Medua Komputinda, n.d.), 152.

${ }^{43}$ Al-Attas, Prolegomena, 85.

${ }^{44}$ Daniel Hayborn, The Pursuit Unhapiness Telusive Psychology of Well Being (New York: Oxford Univeristy Press, 2008).

${ }^{45}$ Richard M. Ryan dan Edward L.Deci, "On Happines and Human Potential: A Review of Research on Hedonic and Eudaimonic Well Being," Annu Rev Pschology (2001): 144.

${ }^{46}$ Franz Magnis Suseno, 13 Tokoh Etika Sejak Zaman Yunani Sampai Abad Ke-19 (Yogyakarta: Kanisius, 1997), 185.

${ }^{47}$ Rusfian Effendi, Filsafat Kebahagiaan (Plato, Aristoteles, Al-Ghazali, Al-Farabi) (Yogyakarta: CV Budi Utama, 2017), 2.

${ }^{48}$ Hasib, "Manusia Dan Kebahagiaan: Pandangan Filsafat Yunani Dan Respon Syed Muhammad Naquib AlAttas," 24-25.

${ }^{49}$ Al-Attas, Prolegomena, 148.
} 
spirituaitas. ${ }^{50}$ Dalam menjalani kehidupan dan mencapai kebahagiaan, manusia menghadapi goncangan dan tekanan berupa strees dan ketidaktenangan hati yang menjadi jiwanya gersang dan memerlukan solusi dalam memecahkan persoalan hidupnya.Hubungan kebahagiaan dan diri sendiri itu menyentuh pada aspek karekter yang baik yang berlandaskan dari ilmu, karena Islam mengajarkan bahwa tempat bersemayamnya pengetahuan pada manusia adalah subtansi spirutual yang secara beragam di tunjuk Al-Qur'an sebagai hati (qalb),jiwa atau diri (nafs) atau intelek ('aql) atau ruh. ${ }^{51}$ Dalam mewujudkan kebahagiaan al-attas memformulasikan penekanan pada tiap individu untuk mengaplikasikan keempat aspek tersebut, karena keempat aspek ini merupakan sesuatu yang saling berkaitan. ${ }^{52}$

Dalam Islam dijelaskan bahwa manusia itu berdasarkan fitrahnya adalah untuk tunduk dan patuh kepada kekuatan transeden yang disebut dengan Tuhan. ${ }^{53}$ Makna agama dalam Islam terdapat dalam kata din, agama dalam makna ini tidak hanya sekedar keyakinan saja, tetapi sebagai konsep yang berwujud suatu sistem kehidupan. ${ }^{54}$ Agama adalah faktor lain yang dapat mempengaruhi diri manusia, agama juga merupakan fitrah serta kebutuhan dasar yang dirasakan oleh setiap insan dalam hatinya. ${ }^{55}$ Maka din memiliki hubungan yang erat dalam diri manusia karena agama merupakan bentuk penyerahan diri dan mengandung tujuan diciptakan manusianya manusia yakni menjalankan ibadah ${ }^{56}$ serta taat kepada Allah dengan hakikat dasar (fitrah)nya.Karena dalam Islam, seorang muslim tidak terikat dengan kontrak sosial, ${ }^{57}$ tetapi ia terikat dengan kontrak pribadi yang mencerminkan perjanjian dalam jiwa antara dirinya dan Allah.

Dengan demikian manusia memerlukan agama sebagai rujukan dan pedoman dalam menjalankan kehidupan dunia. Karena pada dasarnya manusia akan berada pada titik memerlukan kekuatan Tuhan, karena kelemahan yang dimiliki oleh manusia. Dengan adanya agama mampu mengembangkan potensi dan memberikan aspek positif berupa berbuat adi pada dirinya dan oranga lain. Dan agama hadir sebagai untuk menuntun manusia mencapai kebahagiaan yang hakiki, yakni berdasarkan pada keyakinan dan pengamalan berdasarkan worlview Islam.

\section{Worldview sebagai Basis Kebahagiaan}

Worldview merupakan sebuah asas metafisika. Al-Attas menjelaskan bahwa worldview Islam itu merupakan cara pandang terhadap realitas dan kebenaran ${ }^{58}$ serta hubungan yang tidak terpisahkan antara aspek yang terlihat dan yang tidak terlihat yakni antara realitas dunia dan akhirat. Dijelaskannya bahwa aspek dunia harus terkait dengan aspek akhirat, karena aspek akhirat adalah signifikasi terakhir. ${ }^{59}$ Maka dalam hal ini wordview dalam Islam membagai dalam tiga aspek;Pertama, worldview Islam berkaitan erat dengan keberadaan dalam totalitasnya yang meliputi dunia yang terlihat dan yang tidak terlihat.Kedua, visi worldview Islam adalah survei

\footnotetext{
${ }^{50}$ Kholid Muslih et Al, Worldview Islam Pembahasan Tentang Konsep-Konsep Penting Dalam Islam (Ponorogo: UNIDA Gontor Press, 2018), 76.

${ }^{51}$ Al-Attas, Prolegomena, 82.Lihat juga : Syed Muhammad Naquib al-Attas, Ma'na Kebahagiaan Dan Pengamalannya Dalam Islam, 8.

${ }^{52}$ Islamisasi Ilmu Pengetahuan and Syed Muhammad, "Wan Mohd Nor Wan Daud, The Educational Philosophy And Practice of Syed Muhammad Naquib Al-Attas, (Kuala Lumpur: ISTAC, 1998), h.1 14,” 1998, $14-45$.

${ }^{53}$ Makbul Dkk, ed., Al-Qur'an Tajwid Dan Terjemah, Cet-4 (Coedoba- Internasional, 2016).QS. Ar-Rum[30]: 30

${ }^{54}$ Syed Muhammad Naquib al-Attas, "Islam Religion and Morality," in Prolegomena to The Metaphysics of Islam: An Exposition of the Fundamental Elements of the Worldview of Islam (Kuala Lumpur: ISTACT, 1995$), 43-44$.

${ }^{55}$ Raghib As-Sirjani, The Harmony of Humanity Terj. Fuad Syaifudin Nur Dkk (Bandung: Pustaka Setia, 2015), 654.

${ }^{56}$ Dkk, Al-Qur'an Tajwid Dan Terjemah.QS.Adz-Zariyat[51]: 56

${ }^{57}$ Syed Muhammad Naquib al-Attas, Islam Dan Sekularisme, 176.

${ }^{58}$ Syed Muhammad Naquib al-Attas, "The Worldview of Islam: An Outline," in Islam and the Challenge of Modernity: Historical and Contemporary Contexts (Kuala Lumpur: ISTACT, 1994), 26-27.

${ }^{59}$ Abdelaziz Berghout, Introduction to the Islamic Worldview (Kuala Lumpur: IIUM Press, 2009), 8.
} 
metafisik dan pengetahuan yang bertujuan untuk menghapuskan kebingungan dan menetapkan kebenaran realitas.Ketiga, sifat non-dialektis dan non-historisitas dari worldview Islam yang diungkapkan sebagai teks lengkap dan komprehensif.Ia memberikan interpretasi yang jelas dan mendalam tentang kebenaran realitas. ${ }^{60}$ Sederhananya, Al-Attas menekankan bahwa worldview Islam tidak bisa dilepaskan dari hal-hal metafisika.

Worldview dalam Islam itu bukan hanya berorientasi pada keyakinan aqidah, namun merupakan cara pandang sesuatu tentang realitas dan keyakinan terhadap sesuatu yang memiliki wujud dan bersifat metafisik, itu semua memiliki kaitannya dengan Tuhan. Maka worldview dalam Islam memiliki kaitan yang erat antara dunia dan akhirat, sebab dunia merupakan investasi dalam mempersiapkan akhirat. Kemudian pandangan hidup Islam bercirikan pada metode berfikir yanh tawhidi, serta pandangan hidup yang bersumber kepada wahyu, diperkuat oleh agama didukung oleh akal dan intuisi, dan akhirnya akan memberikan konsepsi dasar bahwa pandangn hidup manusia itu tidak hanya berupa kehidupan dunia tapi juga berorientasi pada kehidupan akhirat.

Selanjutnya, Al-Attas mengatakan bahwa elemen asas bagi worldview Islam sangat banyak dan tidak terpisahkan antara satu dengan yang lain. Di antara konsep-konsep yang paling utama adalah konsep tentang hakikat Tuhan, kemudian ada konsep wahyu, penciptaan, hakikat kejiwaan manusia, ilmu, agama, kebebasan, nilai, kebajikan, kebahagiaan dan lain sebagainya yang semua konsep ini akan selalu berkaitan antara satu dengan yang lain. Al-Attas menekankan pada pentingnya konsep sebagai elemen worldview Islam. Karena konsep-konsep ini berhubungan antara satu sama lain yang membentuk sebuah struktur konsep yang sistematik. ${ }^{61}$ Elemen-elemen tersebut sebenarnya memberikan gambaran terhadap visi kehidupan seorang manusia.

Pandangan Al-Attas mengatakan bahwa seseorang harus menekankan bahwa faktanya worldview Islam terungkap dan diimplementasikan secara berangsur-angsur. Yang mana terbentuk dari budaya dan konteks sejarah yang dibimbing langsung oleh al-Qur'an dan as-Sunnah.Walau bagaimanapun, perbedaan antara wahyu dan worldview Muslim adalah penting dalam banyak sebab. Berghout menyebutkan ada lima,

"First, the Quranic text remains the unalterable and unchangeable source of Divine guidance in all aspects. Second, ... is constructed and developed in light of the preserved and complete revealed Qur'anic Divine word of God. Third, ... is a result of the Muslim mind and intellect's interaction with the socio-economic and political-cultural circumstances in light of the QUr'anic guidance and teachings ... Fourth, ... the Muslim undertook a long process of Ijtihad and intellectual efforts to adopt himself to the new teachings of Islam and to realize them in a changing context and reality. "62

Sejalan dengan definisi di atas, Prof. Md. Kamal Hassan mengatakan worldview mengacu kepada "a comprehensive conception of the universe and man's relation to it from the Islamic perspective, thereby serving as a basis for one's philosophy or outlook of life". ${ }^{63}$ Islam juga memiliki konsep ilmu pengetahuan serta konsep kebenaran yang berbeda dengan worldview lainnya. Ilmu pengetahuan dan kebenaran didapat dari sarana internal dan eksternal manusia. Sarana internal berupa indra, rasio, dan intuisi. Sarana eksternalnya berupa Wahyu, ajaran keagamaan yang ditransmisikan melalui sumber otentik lantas merujuk kepada otoritas wahyu, juga

\footnotetext{
${ }^{60}$ Berghout, 9.

${ }^{61}$ Syed Muhammad Naquib al-Attas, "Islam and the Challenge of Modernity," in Proceeding of the Inaugural Symposium on Islam and the Challenge of Modernity: Historical and Contemporary Context (Kuala Lumpur: ISTACT, 1996), 29.

${ }^{62}$ Berghout, Introduction to the Islamic Worldview, 15.

${ }^{63}$ Mohd. Kamal Hassan, The Islamic Worldview', in Towards a Positive Islamic Worldview: Malaysian and American Perceptions, ed. Andul Monir Yaacob and Ahmad Faiz Abdul Rahman (Kuala Lumpur, 1994$), 12$.
} 
informasi terpercaya mengenai suatu hal ilmiah yang merujuk kepada orang yang memiliki otoritas ilmu tersebut. Bukan sekedar pengakuan terhadap kekuatan rasio manusia, apalagi menjadikan manusia sebagai ukuran bagi segala ilmu pengetahuan dan kebenaran. ${ }^{64}$

Al-attas mengisyaratkan bahwa kebahagiaan yang di dapatkan manusia itu merupakan sebuah pengamalan dari pandangan Islam (islamic worldview) sehingga pengamalan ini berlandaskan oleh ilmu dalam pandangan islam dan kemudian berimplikasi pada tercapainya kebahagiaan dalam kehidupan manusia. ${ }^{65}$ Dengan demikian worldview Islam merupakan asas dalam kebahagiaan.Kebahagiaan yang dijelaskan oleh Al-Attas memberikan arti bahwa antara dunia dan akhirat memiliki ikatan yang erat yakni diperuntukan bagi orang-orang yang berserah diri kepada Tuhan dan berpegang erat pada hidayah-Nya.Hal penting yang harus digaris bawahi adalah agama menjadi asas penting dalam mencapai kebahagiaan yang diperoleh dari akal dan wahyu.kebahagiaan yang dijelaskan oleh al-Attas adalah kebahagiaan yang berdasarkan pada ilmu, iman dan perbuatan yang berupa akhlak yang baik. ilmu dan iman merupakan kebenaran yang akan membawa manusia untuk membedakan mana hal yang baik dan mana hal yang buruk sehingga manusia mampu menghasilkan sebuah kondisi yang disebut dengan adil. ${ }^{66}$

Oleh karena itu, al-Attas menegaskan bahwa makna dan hakikat kebahagiaan serta pengamalannya dalam Islam adalah dengan tujuan akhir cinta kepada Allah.Dengan tingkatan kebahagiaan jasmani dan rohani. ${ }^{67}$ Tingkatan jasmani berupa kenikmatan yang bersifat sementara yang dilandasi dengan sifat-sifat baik.Tingkat rohani adalah tingkatan yang dirasakan manusia setelah mampu melalui cobaan dan ujian, dalam hal ini orang-orang yang berada dalam posisi ma'rifatullah (mengenal Allah). Dan akhirnya akan berpuncak pada ketentraman hati dan mampu mencapai kesalihan pikiran dan mampu membawa kepada kesejahteraan jasmani.

\section{Makna Bahagia}

Dalam islam kebahagiaan tidak berubah-ubah, makna dan pengalaman kebahagiaan dalam Islam merujuk pada tiga aspek yakni; pertama, diri (nafsiyah), yang melibatkan ilmu dan sifat yang terpuji. Kedua, badan (badaniyah), seperti kesehatan dan keselamatan.Ketiga, segala yang selain diri dan badan (khairijiyah), seperti kekayaan dan lingkungan. ${ }^{68}$ Adapun hubungan antara kebahagiaan dengan diri itu terdiri dari ilmu sifat terpuji.Islam menegaskan bahwa ilmu adalah tentang makna, yakni memahami arti dari ilmu itu.Dalam hal ini al-Attas membagi definisi ilmu dalam dua bagian.Pertama, ilmu merupakan sesuatu yang berasal dari Allah dan diberikan hanya kepada orang-orang terpilih.Kedua,ilmu merupakan sesuatu yang didapatkan melalui proses observasi dan penelitian yang didasari oleh akalnya sendiri. ${ }^{69}$ Ilmu yang dilandaskan beradasarkan pandangan Islam maka akan melahirkan iman, iman yang berlandakan dengan nilai-nilai tauhid. Adanya iman kemudian muncul sifat terpuji yang merupakan usaha melaksanakan amanah yang diberikan oleh Allah, yakni bukan hanya berikrar dengan lisan, mengakui kebenaran dengan hati serta melaksanakan amalan. Hal ini di benarkan oleh Ibnu Miskawaih menyatakan bahwa kebahagiaan eksistensi ada pada inti perilakunya yang ia lakukan berdasarkan kesemurnaan dan

\footnotetext{
${ }^{64}$ Berghout, Introduction to the Islamic Worldview, 64.

${ }^{65}$ Al-Attas, Prolegomena, 85.

${ }^{66}$ Syed Muhammad Naquib al-Attas, Islam Dan Sekularisme, 93.

${ }^{67}$ Syed Muhammad Naquib al-Attas, Ma'na Kebahagiaan Dan Pengamalannya Dalam Islam, 43.

${ }^{68}$ Syed Muhammad Naquib al-Attas, xi.

${ }^{69}$ Syed Muhammad Naquib Al-Attas, Islam Dan Filsafat Sains (Bandung: Mizan, 1995).lihat jugaL Achmad Reza Hutama Al-Faruqi, "Konsep Ilmu Dalam Islam,” Kalimah 13, no. 2 (2015): 223, https://doi.org/10.21111/klm.v13i2.286.
} 
keutuhan. ${ }^{70} \mathrm{Al}$-attas menjelaskan bahwa sifat terpuji itu terbagi dalam dua kategori, yakni zahir dan batin. Sifat terpuji dalam aspek zahir berupa melakukan amalan-amalan yang dilakukan untuk memenuhi perintah Allah. Seperti melakukan perintah yang difardhukan dan amalan yang melibatkan sesama manusia serta mengamalkan rukun islam dalam seluruh aspek kehidupan. Sedangkan yang aspek batiniyahnya berupa amalan hati yang didasarkan untuk mengenal Allah dan dirinya. Amalan hati dalam hal ini seperti tafakkur yang kemudian melahirkan sifat sabar, tawakkal, syukur, dan rasa takut kepada kemurkaan Allah.

Selain hubungan kebahagiaan dengan diri, adapula hubungan kebahagiaan dengan badaniyyah.Badan manusia dibagi dalam dua entitas yakni jasad dan ruh, dalam kaitannya dengan kebahagiaan jasad dipenuhi dengan makan, minum, tidur, olahraga dan lain sebagainya.Pemenuhan jasadiah berfungsi untuk menjaga kesehatan tubuh.Al-attas menjelaskan bahwa badan memiliki kontribusi penting dalam perkembangan intelektual dan spiritual manusia.Sebab melalui badan atau jasad manusia mampu memperoleh informasi dan data tertentu mengenai dunia dan pengalamannya. ${ }^{71}$ Dan ada pula yang selain dari diri dan badan yakni berupa kekayaan dan lingkungan sekitar. Kesehatan dan kekayaan merupakan suatu kebahagiaan tersendiri bagi manusia, namun perlu di ingat bahwa kebahagiaan itu harus tetap berlandaskan pada nilai-nilai Islam.

Dalam penjelasan makna mengenai kebahagiaan al attas tidaklah membedakan antara kebahagiaan dunai dan akhirat tetapi al-attas justru memadukannya. Al-attas menjelaskan bahwa untuk mendapatkan kebahagiaan di akhirta maka dunai merupakan tempat invetasinya.Dalam pandangan al-attas manusia itu tidak hanya sebagai subjek tetapi juga sebagai objek dari ilmu pengetahuan.terkhusus dalam pemasalahan kebahagiaan, manusia memiliki potensi untuk menjadi objek sekaligus subjek yang merasakan dan mengkaji mengenai kebahagiaan. Al-attas menenkan setiap aktivitas haruslah berlandasakan dengan worldview Islam, agar kebahagiaan yang didapatkan merupakan kebahagiaan yang hakiki. ${ }^{72}$

Dalam hal akhirat, makna kebahagiaan itu merupakan implikasi dari kehidupan di dunia.Hal ini dapat dilihat dari pendapat al-Ghazali, menurutnya kebahagiaan manusia dicapai dengan ilmu, dengan itu manusia mampu mendekatkan diriya kepada Allah. ${ }^{73} \mathrm{Hal}$ senada juga disampaikan alAttas bahwa kebahagiaan itu ilmu yang memberi tempat, keadaannya dinisbahkan kepada Allah. ${ }^{74}$ Kemudian tujuan akhir kebahagiaan adalah cinta kepada Allah (mahabbah), Ibnu Thufail menambahkan bahwa puncaknya kebahagiaan manusia itu ketika dia mampu melihat Allah diakhirat. ${ }^{75}$

\section{Kesimpulan dan Saran}

Dari uraian di atas dapat disimpulkan makna bahagia yang selama ini dipahami oleh kebanyakan ahli terkhusus yang sering disampaiakan para psikolog modern lebih bermkana pada bahagia duniawi semata. Bahagia yang bersifat temporal dan selalu berubah, bukan bahagia yang imatrial atau sesuatu kondisi yang tidak bisa dilukiskan. Berbeda dalam pandangan Islam. Dalam Islam bahagia itu adalah suatu kondisi batin yang sulit untuk dijelaskan tetapi hanya bisa dirasakan. Kondisi yang seperti itu hanya bisa diperoleh dan diperuntukan khusus bagi orang-orang yang tunduk dan taat kepada Allah.

\footnotetext{
${ }^{70}$ Muhammad Utsman Najati, Jiwa Dalam Pandangan Para Filosof Muslim (Bandung: Pustaka Hidayah, 2002).p.95

${ }^{71}$ Wan Mohd Nor Wan Daud, The Educational Philosophy And Practice of Syed Muhammad Naquib Al-Attas, (Kuala Lumpur: ISTAC, 1998), h.1 14."

${ }^{72}$ S.M.N al-Attas, Prolegomena to the Metaphysics of Islam.p. 82

${ }^{73}$ Imam Al-Ghazali, "Kimiya Al-Sa`adah (Kimia Ruhani Kebahagiaan Abadi)," 2001, 159.

${ }^{74}$ S.M.N al-Attas, Prolegomena to the Metaphysics of Islam.p. 89

${ }^{75}$ Najati, Jiwa Dalam Pandangan Para Filosof Muslim.
} 
Kondisi batin yang seperti itu dijelaskan oleh al-Attas yang menyatakan makna kebahagiaan dalam Islam terdiri dari tiga unsur; Pertama, dirinya atas keyakinan yang menatap dalam dirinya. Kedua, aplikasi amal berdasarkan pengetahuan dan pengenalannya. Ketiga, sesuatu yang berada diluar dirinya. Dari aspek-aspek ini al-Attas menjelaskan bahwa makna kebahagiaan itu tidak hanya terbatas dalam dimensi duniawi, seperti yang telah di konsepikan dalam pemikiran Barat. Tetapi, kebahagiaan yang hakiki itu adalah ketika manusia mampu sampai kepada tingkat ma'rifatullah (mengenal Allah).

Selain itu, makna kebahagiaandapat terbagi menjadi dua yakni kebahagiaan jasmani dan rohani. Kebahagiaan jasmani merupakan kebahagiaan yang bersifat sementara seperti kecantikan, kekayaan jabatan sedangkan kebahagiaan rohani merupakan kebahagiaan yang tetap, tidak akan berubah dan hasil dari aktifitas hati yang berserah diri kepada Allah yang akan berpuncak dengan bertemu dan melihat dengan Allah.

\section{E. Daftar Pustaka}

Al-Attas, Syed Muhammad Naquib. "Islam: The Concept of Religion and the Foundation of Ethics and Morality." Prolegomena to The Metaphysics of Islam: An Exposition of the Fundamental Elements of the Worldview of Islam, 1995, 358.

_. Islam Dan Filsafat Sains. Bandung: Mizan, 1995.

. Islam Dan Sekularisme. Bandung: PIMPIN, 2011.

. "Islam Religion and Morality." In Prolegomena to The Metaphysics of Islam: An

Exposition of the Fundamental Elements of the Worldview of Islam. Kuala Lumpur: ISTACT, 1995.

- Ma'na Kebahagiaan Dan Pengamalannya Dalam Islam. Kuala Lumpur: ISTACT, 2002.

—. "The Worldview of Islam: An Outline." In Islam and the Challenge of Modernity: Historical and Contemporary Contexts. Kuala Lumpur: ISTACT, 1994.

- Prolegomena to the Metaphysics of Islam. Kuala Lumpur: International Institute of Islamic Thought and Civilization, 1995.

Al-Faruqi, Achmad Reza Hutama. "Konsep Ilmu Dalam Islam.” Kalimah 13, no. 2 (2015): 223. https://doi.org/10.21111/klm.v13i2.286.

Al-Ghazali, Imam. "Kimiya Al-Sa`adah (Kimia Ruhani Kebahagiaan Abadi),” 2001, 159.

Al-Minsari, Muhammad ibn Mukarrim ibn Manzur al-Anshari al-Ifriqi. Lisan Al-Arab. Kairo: Dar Ibn al-Jauzi, 2015.

Al-Suyuţi, Jalal al-Din al-Mahalli dan Jalal al-Din. Tafsir Al-Jalalayn. Cairo: Dar al-Hadist, n.d.

Al-Zuhaili, Wahbah. No Title. Damaskus: Dar al Fikr al-Mu'ashir, n.d.

Al, Kholid Muslih et. Worldview Islam Pembahasan Tentang Konsep-Konsep Penting Dalam Islam. Ponorogo: UNIDA Gontor Press, 2018.

Arif, Mahmud. Pendidikan Islam Transformatif. Yogyakarta: LKis, n.d.

Aristotle. "Nicomachean Ethic." In Book I Terj. Roger Crisp. UK: Cambridge University Press, n.d.

Arroisi, Jarman. "Bahagia Dalam Perspektif Al-Ghazali." Kalimah 17, no. 1 (2019): 89. https://doi.org/10.21111/klm.v17i1.2942.

As-Sirjani, Raghib. The Harmony of Humanity Terj. Fuad Syaifudin Nur Dkk. Bandung: Pustaka Setia, 2015.

Berghout, Abdelaziz. Introduction to the Islamic Worldview. Kuala Lumpur: IIUM Press, 2009.

Bertens, Kees. Sejarah Filsafat Yunani. Yogyakarta: Kanisius, n.d.

Budiarta. Metodologi Penelitian Kesehatan Dengan Contoh Bidang Ilmu Kesehatan Gigi. Jakarta: Buku Kedokteran EGC, 20006.

Danim, Sudarwan. Riset Keperawatan: Sejarah Dan Metodologi. Jakarta: Buku Kedokteran EGC, 
2002.

Diener, Ed. Personality, Culture, and Subjective Well Being of Nation. Chicago: The University of Chicago Press, 2009.

Dkk, Makbul, ed. Al-Qur'an Tajwid Dan Terjemah. Cet-4. Coedoba- Internasional, 2016.

Effendi, Rusfian. Filsafat Kebahagiaan (Plato, Aristoteles, Al-Ghazali, Al-Farabi). Yogyakarta: CV Budi Utama, 2017.

Hasan, M. Iqbal. Pokok-Pokok Materi Penulisan Dan Aplikasinya. Jakarta: Ghalia Indonesia, 2002.

Hasib, Kholili. "Manusia Dan Kebahagiaan: Pandangan Filsafat Yunani Dan Respon Syed Muhammad Naquib Al-Attas." Tasfiyah 3, no. 1 (2019): 21. https://doi.org/10.21111/tasfiyah.v3i1.2980.

Hassan, Mohd. Kamal. The Islamic Worldview', in Towards a Positive Islamic Worldview: Malaysian and American Perceptions. Edited by Andul Monir Yaacob and Ahmad Faiz Abdul Rahman. Kuala Lumpur, 1994.

Hayborn, Daniel. The Pursuit Unhapiness Telusive Psychology of Well Being. New York: Oxford Univeristy Press, 2008.

Hidayat, Komaruddin. Psikologi Kebahagian Merawat Bahagia Tiada Akhir. Jakarta: Books, 2013. Kaelan. Metodologi Penelitian Kualitatif Interdisipliner Bidang Sosial, Budaya, Filsafat, Seni, Agama Dan Humaniora. Yogyakarta: Paradigma, 2012.

Katsir, Ibnu. Tafsîr Al-Qur'an Al-Adhim. T.Kota: Dar Tayyibah, 1999.

Kebudayaan, Departemen Pendidikan dan. Kamus Besar Bahasa Indonesia. Jakarta: Balai Pustaka, 1990.

Koren, Henri J. Research in Philosophy. USA: Dequesne University, 1966.

Kountur, Ronny. Metode Penelitian Untuk Penulisan Skripsi Dan Tesis. Jakarta: Buana Printing, 2009.

L.Deci, Richard M. Ryan dan Edward. "On Happines and Human Potential: A Review of Research on Hedonic and Eudaimonic Well Being." Аnnu Rev Pschology Annual Rev (2001).

Lopez, C.R. Snyder \& Shane J. Positive Psycology: The Saintific And Practical Exploration Of Human Strenght. California: Sage Publication, 2007.

Manzur, Muhammad bin Mukrim bin. Lisānul Arab. Beirut: Dār Șadir, n.d.

Mauludi, Sahrul. Aristoteles Inspirasi Dan Pencerahan Untuk Hidup Lebih Bermakna. Jakarta: T Elex Medua Komputinda, n.d.

Mudzar, M. Aatho. Pendekatan Studi Islam Dalam Teori Dan Praktek. Yogyakarta: Pustaka Pelajar, 1992.

Najati, Muhammad 'Utsman. Jiwa Dalam Pandangan Filosof Muslim, Terj:Dazi Saloom. Bandung: Pustaka Hidayah, 2002.

Najati, Muhammad Utsman. Jiwa Dalam Pandangan Para Filosof Muslim. Bandung: Pustaka Hidayah, 2002.

Nasiona, Pusat Bahasa Departemen Pendidikan. Kamus Bahasa Indonesia. Jakarta: Pusat Bahasa, 2008.

Nata, Abuddin. Metodologi Studi Islam. Jakarta: Raja Wali Press, 2013.

Nazir, Moh. Metode Penelitian. Edited by Risman F. Sikumbang. Cet-8. Bogor: Ghalia Indonesia, 2013.

Pengetahuan, Islamisasi Ilmu, and Syed Muhammad. "Wan Mohd Nor Wan Daud, The Educational Philosophy And Practice of Syed Muhammad Naquib Al-Attas, (Kuala Lumpur: ISTAC, 1998), h.1 14," 1998, 14-45.

Rahardjo, Mudjia. Analisis Muatan Sebagai Metode Pengukuran Kata Pengantar Dalam Nanang 
Martono, "Metode Penelitian Kualitatif Analisis Isi Dan Analisis Data Sekunder. Jakarta: PT Raja Gravindo Persada, 2014.

Rofi'udin. "Konsep Kebahagiaan Dalam Pandangan Psikologi Sufistik." Theologia 24, no. 2 (2013): 1-37.

Ryff, C.D. "Happiness Is Everything, Or Is It? Explorations On The Meaning Of Psychological Well-Being." Journal Of Personality And Social Psychology Vol. 57 (1989).

Seligman, Martin. , Authentic Happiness: Using the New Positive Psychology to Realize Your Potential for Lasting Fulfillment. New York: Free Press, 2002.

Singarimbun, Masri. Metodologi Penulisan Survey. Jakarta: LP3ES, n.d.

Smith, S. Stephenson. The New International Webster's Comprehensive Dictionary Of The English Language: Deluxe Encyclopedic Ed. Chicago: J.G. Ferguson Publishing, 1996.

Sumodiningrat, Gunawan. Pemberdayaan Sosial: Kajian Ringkas Tentang Pembangunan Manusia Indonesia. Jakarta: Buku Kompas, n.d.

Suseno, Franz Magnis. 13 Tokoh Etika Sejak Zaman Yunani Sampai Abad Ke-19. Yogyakarta: Kanisius, 1997.

Syam, Syahril. Secret of Attaractor Factor. Jakarta: Gramedia, 2008.

Syed Muhammad Naquib al-Attas. "Islam and the Challenge of Modernity." In Proceeding of the Inaugural Symposium on Islam and the Challenge of Modernity: Historical and Contemporary Context. Kuala Lumpur: ISTACT, 1996.

"Https://Www.Oxfordlearnersdictionaries.Com/Definition/English/Happiness?Q=happiness.," n.d. Https://Oxford.Universitypressscholarship.Com/View/10.1093/Acprof:Oso/9780199926725.001.00 01/Acprof-9780199926725-Chapter-20," n.d.

The Merriam Webster Online Dictionary. "Https://Www.Merriam-Webster.Com/," n.d. 